\title{
Re: Welk, et al., an opioid prescription for men undergoing minor urologic surgery is associated with an increased risk of new persistent opioid use
}

\author{
Dmitry Enikeev ${ }^{1}$, Mark Taratkin ${ }^{1}$, Nikolai Lavrinenko ${ }^{1}$, Alexander Panferov ${ }^{2}$, Nirmish Singla ${ }^{3}$ \\ ${ }^{1}$ Institute for Urology and Reproductive Health, Sechenov University, Moscow, Russia; ${ }^{2}$ Department of Internal Diseases, Sechenov University, \\ Moscow, Russia; ${ }^{3}$ Department of Urology, University of Texas Southwestern Medical Center, Dallas, TX, USA \\ Correspondence to: Dmitry Enikeev. Deputy Director for Research, Institute for Urology and Reproductive Health, Sechenov University, 2/1, Bolshaya \\ Pirogovskaya str., Moscow, Russia. Email: dvenikeev@gmail.com. \\ Comment on: Welk B, McClure JA, Clarke C, et al. An Opioid Prescription for Men Undergoing Minor Urologic Surgery Is Associated with an \\ Increased Risk of New Persistent Opioid Use. Eur Urol 2020;77:68-75.
}

Submitted Apr 22, 2020. Accepted for publication May 11, 2020.

doi: $10.21037 /$ tau-20-884

View this article at: http://dx.doi.org/10.21037/tau-20-884

The increasing opioid dependence in North America is undoubtedly one of the most disturbing healthcare and social problems (1). Growth of opioid prescriptions in the USA over the last 20 years has substantially contributed to opioid dependence (2). For more than a century, opioids were an essential part of healthcare as one of the most effective options for analgesia $(3,4)$. Nonetheless, according to WHO, opioid abuse remains one of the leading causes of death among drug users (5), and the USA holds the leadership in opioid use. A 2019 report by the International Narcotics Control Board shows that this country consumes up to $40 \%$ of all opioids; however, its opioid-using population only constitutes $5.3 \%$ among all the contributing countries (6).

Welk et al. provided another indication that the opioid epidemic is an important problem for North American healthcare (1). The authors analyzed the databases of Ontario's public health registries and enrolled data of 91,083 men who underwent urologic surgeries that should not require post-procedure opioid prescriptions or only a short course. The findings were as follows: more than a third of patients (35\%) were prescribed opioids; of them, $81 \%$ were prescribed by urologists which led to increased risk of opioid dependence for both types of procedures (adjusted OR 1.37, 95\% CI: 0.92-2.04, P=0.12 and adjusted OR $1.46,95 \%$ CI: $1.28-1.67, \mathrm{P}<0.01)$. While the paper by Welk et al. is a perfect example of the potential harm of opioid prescription, it does not provide a clear answer to the question of who is responsible for the overwhelming opioid abuse. Previously, several possible factors were suggested: initial reports stating that opioids were safe, aggressive marketing, and pill-mills - clinics that prescribe opioids unnecessarily (2).

Most of the sources suggest that the current opioid crisis in the USA could be a consequence of healthcare reformation in the 1990's when pharmaceutical companies provided a large body of evidence that opioids were a safe option for fast pain relief (7-9). Until recently, a number of opioid usage advocates referred to a 40-year-old letter published in the New England Fournal of Medicine, in which the authors reported a minimal number of opioid abuse cases (4 among almost 12,000 patients) (7). This brief letter was cited more than 600 times over 40 years. In 2017, it was heavily criticized by Leung et al., who pointed out that more than $72.2 \%$ of citations of this paper were used as evidence of opioid addiction rarity (8). The authors hold the view that the citation contributed substantially to opioid abuse in North America "by helping to shape a narrative that allayed prescribers' concerns about the risk of addiction associated with long-term opioid therapy". Leung et al. suggested that most of the instances of letter citation were carried out in favor of pharmaceutical companies marketing opioids (8). Does it imply that pharmaceutical companies are the driving force behind the current crisis? Indeed, aggressive and treacherous marketing by some companies has been demonstrated. Helmerhorst et al. pointed out that in 2006, Purdue Pharma had been found guilty of irresponsible 
marketing of opioids. However, devious pharmaceutical companies were not the only ones responsible for the crisis (9).

Currently, there are several well-designed trials that testify to the safety of opioid use $(10,11)$. Moreover, in 2010 most of the data on the topic was summarized in a Cochrane review by Noble $e t a l$. in which the authors concluded that the rate of addiction in patients receiving opioids is small (12). However, as the authors point out, this is only true for chronic pain relief.

For these patients, the World Health Organization developed the so-called "pain ladder" (13). At first, healthcare providers should prescribe non-opioid analgesics [aspirin, paracetamol and other nonsteroidal anti-inflammatory drugs (NSAID) or acetaminophen]; then, if the drugs fail to relieve the pain, mild opioids (codeine) can be prescribed. And only then, strong opioids (such as morphine) may be used until the patient is free of pain. While it was initially created for patients with cancer, the pain ladder is a clear strategy for all patients with chronic or postoperative pain. Most of the doctors around the world adhere to this guideline. However, Welk et al. point out that $96 \%$ of all prescriptions (at least 30,000 !) were almost exclusively given by urologists on the first postoperative day (1). This likely means that only $4 \%$ of all prescribed drugs were given correctly, for the pain that could not be relieved by NSAIDs. The ultimate argument from Welk et al. is the fact that median morphine equivalents (MEQs) in their study were found to excel the usually prescribed 3-4 times!

North American clinics have almost no limitations in prescription of opioids. Recently, some states in the US have shortened the maximum length of opioid prescription (14). This strategy is effective in decreasing the number of drug addicts, yet it does not solve the core issue. Many doctors fully realize the importance of the search for immediate and effective pain relief. The use of the WHO pain ladder could be associated with unnecessary consultations or additional tests; or maybe doctors would just want to provide effective pain relief while being sure that opioids would not cause dependency (13).

Recently, results from the prospective, non-randomized, pre-post interventional ORIOLES (Opioid Reduction Intervention for Open, Laparoscopic, and Endoscopic Surgery) trial were published as an initiative to reduce postdischarge opioid prescribing and use, while increasing disposal, after radical prostatectomy (15). The authors further identified risk factors for increased opioid use, including greater prescribing of opioids at discharge, higher body mass index, and use of opioid medication prior to surgery. The same group developed procedure-specific recommendations for 16 endourological and minimally invasive urological procedures to aid quality improvement efforts to reduce overprescribing in urology (16).

A possible solution for the crisis could be the spread of the results of opioid studies. All the efforts to decrease pillmill numbers or fight against dishonest pharmaceutical companies would only have minor effect unless the medical society is well-informed on the possible outcomes of opioid abuse and possible ways to effectively manage pain without addictive drugs.

\section{Acknowledgments}

Funding: None.

\section{Footnote}

Provenance and Peer review: This article was commissioned by the editorial office, Translational Andrology and Urology. The article did not undergo external peer review.

Conflicts of Interest: All authors have completed the ICMJE uniform disclosure form (available at http://dx.doi. org/10.21037/tau-20-884). The authors have no conflicts of interest to declare.

Ethical Statement: The authors are accountable for all aspects of the work in ensuring that questions related to the accuracy or integrity of any part of the work are appropriately investigated and resolved.

Open Access Statement: This is an Open Access article distributed in accordance with the Creative Commons Attribution-NonCommercial-NoDerivs 4.0 International License (CC BY-NC-ND 4.0), which permits the noncommercial replication and distribution of the article with the strict proviso that no changes or edits are made and the original work is properly cited (including links to both the formal publication through the relevant DOI and the license). See: https://creativecommons.org/licenses/by-nc-nd/4.0/.

\section{References}

1. Welk B, McClure JA, Clarke C, et al. An Opioid

Prescription for Men Undergoing Minor Urologic Surgery Is Associated with an Increased Risk of New Persistent Opioid Use. Eur Urol 2020;77:68-75.

2. Verhamme KMC, Bohnen AM. Are we facing an opioid 
crisis in Europe? Lancet Public Health 2019;4:e483-4.

3. UNODC (United Nations Office on Drugs and Crime). Analysis of drug markets. In: World Drug Report 2018. 2018. p. 1-72.

4. Belzak L, Halverson J. The opioid crisis in Canada: A national perspective Health Promot Chronic Dis Prev Can 2018;38:224-33.

5. WHO Information sheet on opioid overdose [Internet]. 2018 [cited 2020 Apr 19]. Available online: https://www. who.int/substance_abuse/information-sheet/en/

6. International Narcotics Control Board. Narcotic Drugs Technical Report [Internet]. [cited 2020 Apr 19]. Available online: https://www.incb.org/incb/en/narcotic-drugs/ Technical_Reports/narcotic_drugs_reports.html

7. Porter J, Jick H. Addiction Rare in Patients Treated with Narcotics. N Engl J Med 1980;302:123.

8. Leung PTM, Macdonald EM, Stanbrook MB, et al. A 1980 Letter on the Risk of Opioid Addiction. N Engl J Med 2017;376:2194-5.

9. Helmerhorst GTT, Teunis T, Janssen SJ, et al. An epidemic of the use, misuse and overdose of opioids and deaths due to overdose, in the United States and Canada: is Europe next? Bone Joint J 2017;99-B:856-64.

10. Kalso E, Simpson KH, Slappendel R, et al. Predicting long-term response to strong opioids in patients with low back pain: findings from a randomized, controlled trial of transdermal fentanyl and morphine. BMC Med 2007;5:39.
11. Likar R, Kayser H, Sittl R. Long-term management of chronic pain with transdermal buprenorphine: A multicenter, open-label, follow-up study in patients from three short-term clinical trials. Clin Ther 2006;28:943-52.

12. Noble M, Treadwell JR, Tregear SJ, et al. Long-term opioid management for chronic noncancer pain. Cochrane Database Syst Rev 2010;2010:CD006605.

13. World Health Organization. WHO's cancer pain ladder for adults [Internet]. World Health Organisation. 1986. Available online: http://www.who.int/cancer/palliative/ painladder/en/

14. Arizona Department of Health Services. 50 State Review on Opioid Related Policy [Internet]. Available online: https://www.azdhs.gov/documents/prevention/womenschildrens-health/injury-prevention/opioid-prevention/50state-review-printer-friendly.pdf

15. Patel HD, Faisal FA, Patel ND, et al. Effect of a prospective opioid reduction intervention on opioid prescribing and use after radical prostatectomy: results of the Opioid Reduction Intervention for Open, Laparoscopic, and Endoscopic Surgery (ORIOLES) Initiative. BJU Int 2020;125:426-32.

16. Koo K, Faisal F, Gupta N, et al. Recommendations for Opioid Prescribing after Endourological and Minimally Invasive Urological Surgery: An Expert Panel Consensus. J Urol 2020;203:151-8.
Cite this article as: Enikeev D, Taratkin M, Lavrinenko N, Panferov A, Singla N. Re: Welk, et al., an opioid prescription for men undergoing minor urologic surgery is associated with an increased risk of new persistent opioid use. Transl Androl Urol 2020;9(5):2299-2301. doi:10.21037/tau-20-884 